Design, Fabrication, and Performance of Foil Gas Thrust Bearings for Microturbomachinery Applications

\author{
Brian Dykas \\ Case Western Reserve University, Cleveland, Ohio \\ Robert Bruckner, Christopher DellaCorte, and Brian Edmonds \\ Glenn Research Center, Cleveland, Ohio \\ Joseph Prahl \\ Case Western Reserve University, Cleveland, Ohio
}




\section{NASA STI Program . . . in Profile}

Since its founding, NASA has been dedicated to the advancement of aeronautics and space science. The NASA Scientific and Technical Information (STI) program plays a key part in helping NASA maintain this important role.

The NASA STI Program operates under the auspices of the Agency Chief Information Officer. It collects, organizes, provides for archiving, and disseminates NASA's STI. The NASA STI program provides access to the NASA Aeronautics and Space Database and its public interface, the NASA Technical Reports Server, thus providing one of the largest collections of aeronautical and space science STI in the world. Results are published in both non-NASA channels and by NASA in the NASA STI Report Series, which includes the following report types:

- TECHNICAL PUBLICATION. Reports of completed research or a major significant phase of research that present the results of NASA programs and include extensive data or theoretical analysis. Includes compilations of significant scientific and technical data and information deemed to be of continuing reference value. NASA counterpart of peer-reviewed formal professional papers but has less stringent limitations on manuscript length and extent of graphic presentations.

- TECHNICAL MEMORANDUM. Scientific and technical findings that are preliminary or of specialized interest, e.g., quick release reports, working papers, and bibliographies that contain minimal annotation. Does not contain extensive analysis.

- CONTRACTOR REPORT. Scientific and technical findings by NASA-sponsored contractors and grantees.

- CONFERENCE PUBLICATION. Collected papers from scientific and technical conferences, symposia, seminars, or other meetings sponsored or cosponsored by NASA.

- SPECIAL PUBLICATION. Scientific, technical, or historical information from NASA programs, projects, and missions, often concerned with subjects having substantial public interest.

- TECHNICAL TRANSLATION. Englishlanguage translations of foreign scientific and technical material pertinent to NASA's mission.

Specialized services also include creating custom thesauri, building customized databases, organizing and publishing research results.

For more information about the NASA STI program, see the following:

- Access the NASA STI program home page at http://www.sti.nasa.gov

- E-mail your question via the Internet to help@ sti.nasa.gov

- Fax your question to the NASA STI Help Desk at 301-621-0134

- Telephone the NASA STI Help Desk at 301-621-0390

- Write to: NASA Center for AeroSpace Information (CASI) 7115 Standard Drive Hanover, MD 21076-1320 


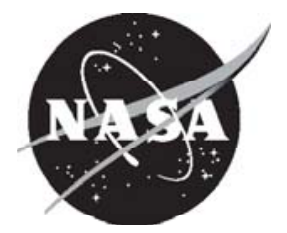

\title{
Design, Fabrication, and Performance of Foil Gas Thrust Bearings for Microturbomachinery Applications
}

\author{
Brian Dykas \\ Case Western Reserve University, Cleveland, Ohio \\ Robert Bruckner, Christopher DellaCorte, and Brian Edmonds \\ Glenn Research Center, Cleveland, Ohio \\ Joseph Prahl \\ Case Western Reserve University, Cleveland, Ohio
}

Prepared for the

Turbo Expo 2008 Gas Turbine Technical Congress and Exposition sponsored by the American Society of Mechanical Engineers

Berlin, Germany, June 9-13, 2008

National Aeronautics and

Space Administration

Glenn Research Center

Cleveland, Ohio 44135 


\section{Acknowledgments}

The authors wish to acknowledge the support of the Fundamental Aeronautics Program Office, Subsonic Rotary Wing Project. Additionally, Chuck Smalley, Jean Wells, and the students of the Pre-Apprentice Machining Program are acknowledged for their skill and effort in constructing much of the prototype tooling and hardware for this study.

This report is a preprint of a paper intended for presentation at a conference.

Because changes may be made before formal publication, this preprint is made available with the understanding that it will not be cited or reproduced without the permission of the author.

Level of Review: This material has been technically reviewed by technical management.

Available from

NASA Center for Aerospace Information 7115 Standard Drive

Hanover, MD 21076-1320
National Technical Information Service 5285 Port Royal Road Springfield, VA 22161

Available electronically at http://gltrs.grc.nasa.gov 


\title{
Design, Fabrication, and Performance of Foil Gas Thrust Bearings for Microturbomachinery Applications
}

\author{
Brian Dykas \\ Case Western Reserve University \\ Cleveland, Ohio 44106 \\ Robert Bruckner, Christopher DellaCorte, and Brian Edmonds \\ National Aeronautics and Space Administration \\ Glenn Research Center \\ Cleveland, Ohio 44135 \\ Joseph Prahl \\ Case Western Reserve University \\ Cleveland, Ohio 44106
}

\begin{abstract}
A methodology for the design and construction of simple foil thrust bearings intended for parametric performance testing and low marginal costs is presented. Features drawn from a review of the open literature are discussed as they relate to bearing performance. The design of fixtures and tooling required to fabricate foil thrust bearings is presented, using conventional machining processes where possible. A prototype bearing with dimensions drawn from the literature is constructed, with all fabrication steps described. A load-deflection curve for the bearing is presented to illustrate structural stiffness characteristics. Startstop cycles are performed on the bearing at a temperature of $425^{\circ} \mathrm{C}$ to demonstrate early-life wear patterns. A test of bearing load capacity demonstrates useful performance when compared with data obtained from the open literature.
\end{abstract}

\section{Introduction}

Foil gas bearings represent an enabling technology for advanced oil-free turbomachinery systems. Operating at high speeds and temperatures, these next-generation turbomachines will present tribological challenges that conventional oillubricated rolling element bearings may be unable to meet, including shaft speeds well above three million DN and bearing temperatures in excess of $400^{\circ} \mathrm{C}$ [1]. Continued advancement of foil bearing technology will allow more widespread adoption of oil-free shaft supports in high speed rotating equipment.

As described by DellaCorte et al. [2], machine designers have been slow to adopt this technology into candidate systems due to the relatively small number of foil bearing manufacturers and a perception of risk. Beyond a specific expertise in the details of gas dynamic lubrication, the fabrication of foil bearings requires a technical knowledge of metallurgy, sheet metal forming, and tribology, dissuading many from attempting their manufacture and development. The information presented herein attempts to provide a basic methodology for the production of prototype thrust bearings for technology evaluation and research.

A further motive for describing the fabrication of foil thrust bearings is the relative dearth of information in the open literature regarding their design, construction, and performance, especially when compared to their journal bearing counterparts. The patent literature contains many references to design practices for the compliant structure supporting the top foil, but only a handful of authors have presented experimental evaluations of performance [3].

Those experimental evaluations are a necessary and critical part of the design effort. Valco and DellaCorte [4] recommend a four-step approach for transitioning foil bearing technology into specific turbomachines: 1) concept feasibility assessment; 2) bearing component development and testing; 3 ) simulated rotor system testing; and 4) turbomachinery system demonstration. This process provides a staged approach to bearing integration that mitigates technical risk with each step.

Performance guidelines have been established to predict journal bearing load capacity [1] and power loss performance [5] for the initial concept feasibility step. The open literature contains many examples of bearing component development and testing (see [2] for a brief discussion of journal bearing devel- 
opment history). Similar guidelines for foil thrust bearings have not yet been validated however, and fewer details of thrust bearing development and testing are freely available. Simulated rotor testing can be performed with facilities such as described by Howard [6], but this type of testing focuses mostly on the radial (orbit) motion of the shaft, whereas thrust loading is more difficult to simulate. The net result is that foil thrust bearing tools have not experienced the same degree of development as those for journal bearings, increasing the technical risk in transitioning them to new turbomachines.

To ameliorate some of the challenges in thrust bearing development, DellaCorte et al [7] have suggested that oil-free turbomachine designs should attempt to minimize thrust loads to reduce load capacity requirements and improve design margin. They also suggest that with lower thrust loading, bearings can be sized smaller to reduce power loss and cooling requirements, driving overall system efficiency higher. Furthermore, lower thrust loads allow a reduction in rotating mass and inertia due to a smaller thrust runner, which can improve the rotordynamic characteristics of the shaft. While conventional rolling element bearing-supported machines are designed to always have a net positive thrust load to prevent skidding of the rolling elements, foil bearings do not require, nor do they benefit from this practice. Consequently, somewhat different design practices are required and employed in foil bearing-supported systems.

\section{Background}

Foil bearings are hydrodynamic bearings composed of compliant surfaces and generally employ a gaseous lubricant. In both geometries a rotating member drags the viscous process fluid into a converging gap, raising the fluid pressure and providing a load carrying capacity. Figures 1 and 2 show the basic components of journal and thrust foil bearings.

Foil bearings were first reported in the open literature by Blok and Van Rossum [8]. These early tension-dominated oillubricated bearings were found to allow thicker fluid films than rigid geometry bearings under a given loading condition, and their compliance provides increased tolerance to misalignment, shock loading, rotor distortions due to centrifugal and thermal stresses, and other deviations from optimal geometry. This tolerance to component-level and system-level geometric distortions is particularly important when using a thin gas film as opposed to a relatively thick viscous oil film. Bending-dominated foil journal bearings followed, with a smooth sheet metal foil providing the bearing surface, and reinforced by a compliant foil support structure. Some of the earliest compliant thrust bearings were more of an outgrowth of predecessor step and tilting pad bearings than a revolution in design and function.

Common practice in modern foil bearings is to use corrugated "bump foils" to form the compliant structure, with many designs incorporating several layers of bump foils to tailor stiff-

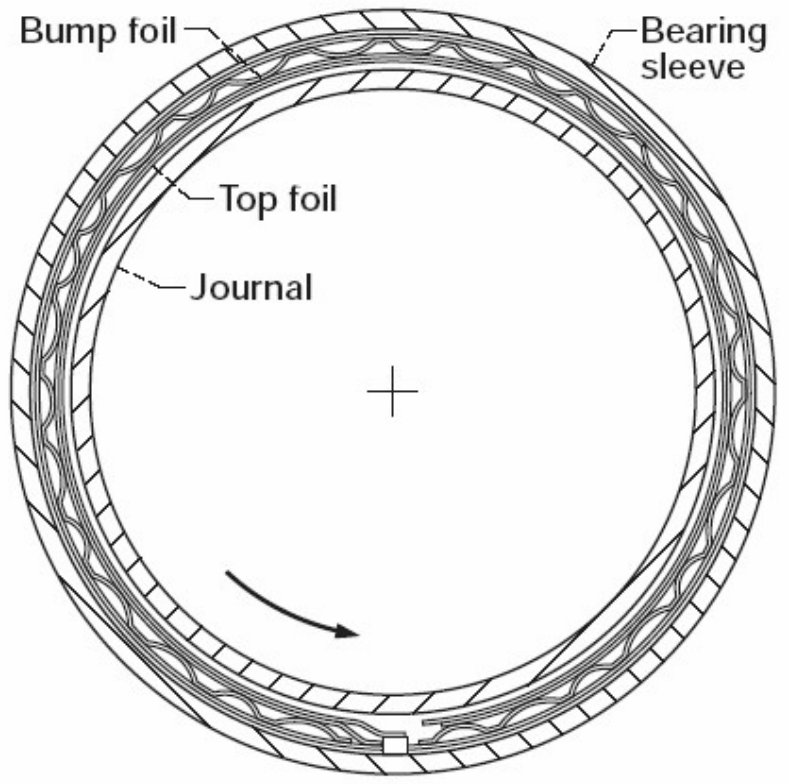

Figure 1. Typical Geometry of a Modern Foil Journal Bearing

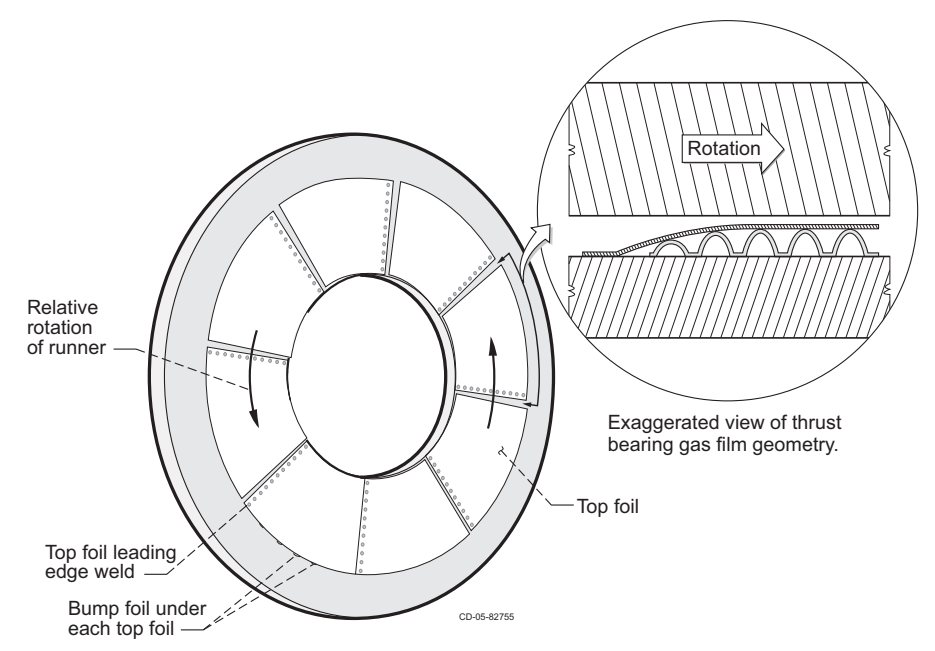

Figure 2. Typical Geometry of a Modern Foil Thrust Bearing

ness properties as a function of bearing loading [9]. The further use of "stiffener foils" between the top and bump foils is an established practice to allow optimization of the bearing deflection behavior. DellaCorte and Valco [1] provide a simple relationship to estimate journal bearing load capacity at various operating conditions, where it is found that the increased complexity of bearings with these features allows for several-fold improve- 
ments in bearing load capacity over the simplest designs.

The patent literature shows an abundance of alternative designs for foil journal bearings including multipad and overlapping "leaf" designs [10], [11], with early foil thrust bearing designs employing similar configurations. However, the earliest foil thrust bearing patents incorporate more advanced design features than are seen in the first foil journal bearing patents. In the first appearance of a bump-foil type thrust bearing in the patent literature [12], a bearing is described with multiple smooth foils tailored to provide speed- and load-dependent deflection behavior for increased load capacity.

This multistage, deflection-dependent bearing stiffness is described as a key feature in modern high load capacity foil journal bearings, though more often achieved by multiple bump layers [9]. Furthermore, descriptions of variable stiffness in the radial [10] and azimuthal [13] directions of the pad appear in the early patents. A number of patents describe a stiffness distribution matching that of the pressure distribution as a technique to increase load capacity [14] [15].

It is notable that in contrast to journal bearings, typical thrust bearing configurations result in large differences between runner surface velocities at the inner and outer diameters of the thrust pads. Bump foil structures must be designed to provide appropriate stiffness distributions to account for these gradients in runner surface velocity.

Another effect described in the literature is crowning of the runner surface. Here, the heat input from viscous dissipation in the gas film leads to an axial temperature gradient in the thrust runner, resulting in a convex rotating surface. Early patents acknowledge the effectiveness of a compliant foundation in compensating for this phenomenon [10] [14], and describe structural tailoring as a way to combat its deleterious effects [16]. Centrifugal stress distortions in the rotating runner can also be accommodated by a compliant bearing surface.

Tailoring of the bearing stiffness distribution to accommodate system-level effects, such as misalignment, also appears in the early literature. Gray and Heshmat [16] describe a bearing whose outer sections are more compliant than inner sections, allowing increased deflection at the outermost radius of the bearing, preventing high speed rubbing contact.

Although a review of patent disclosures yields a wide array of techniques for increasing thrust bearing performance, only a few studies have been published providing experimentally measured bearing performance [17] [18], with these focusing mainly on simpler bearing designs. Specific details of advanced bearing designs remain proprietary and protected under U.S. patent law, thereby restricting the availability of performance data for state-of-the-art bearings. Despite these restrictions, a number of advanced features are described in expired patents and are therefore freely available to would-be bearing designers. A modular foil thrust bearing architecture facilitates the parametric evaluation of the effectiveness of these features. In the sections that follow, a basic design is developed, fabricated, tested, and discussed. The primary purpose of this work, however, is to demonstrate the manufacturing process in order to stimulate more widespread adoption of the technology.

\section{Design Features}

The baseline test bearing is designed to have several discrete pads composed of three major components: a top foil to provide the stationary boundary for the hydrodynamic gas film, a bump foil structure to provide compliant support for the top foil, and the thrust bearing backing plate, as shown in Figure 2. In more advanced bearings, multistage bump foils [9] and reinforcing stiffener foils [13], are generally incorporated into this basic design.

Many foil thrust bearing designs rely on the use of spot or tack welds to attach the foil members to the rigid backing plate. This attachment method can have adverse effects, as noted by DellaCorte, et al. [2], particularly if the individual bearing components are heat treated prior to welding. Additionally, welding precludes the ability to remove and reinstall the foil components, which is conducive to rapid and inexpensive bearing design iterations, as well as increased instrumentation access.

In an attempt to produce a versatile thrust bearing design which provides ample access for instrumentation, such as thermocouples and heat flux gauges affixed directly to the underside of the top foil, welding is not used. Instead, the backing plate is slotted to allow the top foils to be easily installed and removed, as shown in Fig. 3. For simplicity, a partial-arc circular slot is cut into the plate at the leading edge of each pad so that the top foil is restrained tangentially by a curled-over tab, shown in Fig. 4 . This attachment method is similar to a circular mounting slot proposed by Agrawal and Hockey [19]. An identical slot on the trailing edge allows the bump foil to be attached in the same manor. This provides higher stiffness at the trailing edge of the pad [20] [21] to preserve the converging film under load. Alternate arrangements are also envisioned, including one or more bump foils attached at the leading edge of the pad, or incorporating a stiffener foil attached at either the leading or trailing edge. As opposed to a configuration where many foil layers are fastened together in a stacked arrangement [21], [22], this configuration requires a minimal amount of tooling and specialized forming equipment for subsequent iterations in design. The authors do not claim that this specific architecture will result in optimized performance, but it is conducive to relatively rapid and inexpensive technology evaluation, provided suitable test facilities are available.

A further advantage of the curled-over leading edge of the top foil is that it provides a smooth transition region for the process fluid at the leading edge. Whereas welding the top foils to precision spacer blocks can, with care, provide better dimensional accuracy, the curled region provides increased tolerance to 


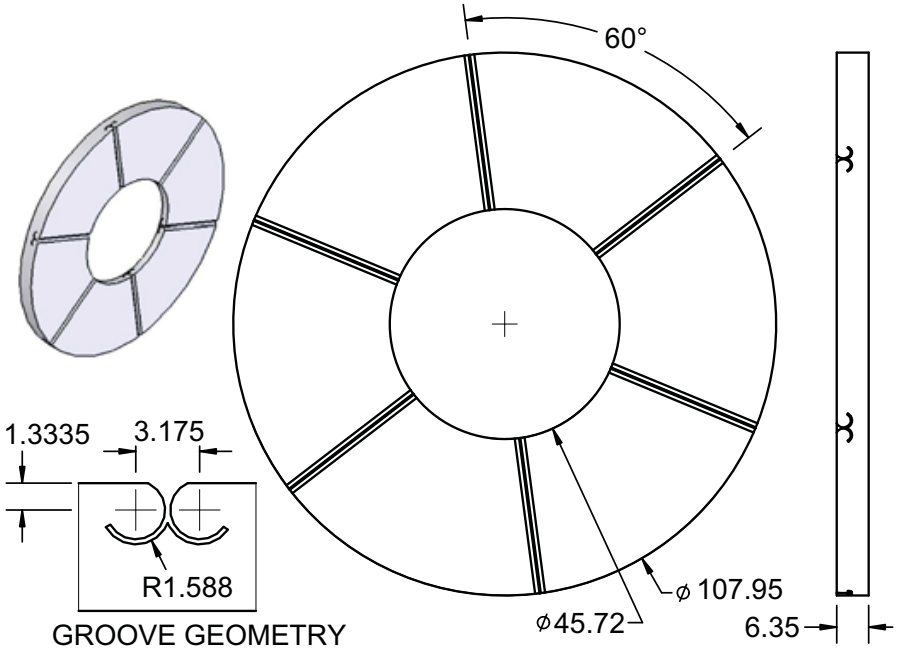

Figure 3. Drawing of Bearing Backing Plate with Foil-Retaining Slots (dimensions in $\mathrm{mm}$ )

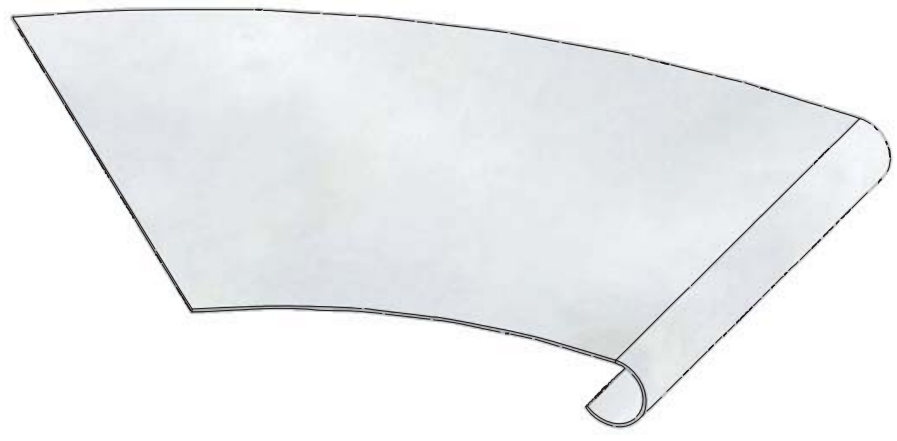

Figure 4. Sketch of Top Foil with Hinged Leading Edge

misalignment at the entrance region. It is also notable that this slot arrangement provides slight hinging motion to allow the top foil to seat on the bump foils more repeatably.

When the bearing is assembled, tack-welded shims are inserted into the curled slots at the inner radius and outer radius of the foil to prevent radial sliding of the foil components. The shims can be removed easily to allow mass-based measurements of top foil wear volume, as well as attachment of fine gauge thermocouples, heat flux gauges, and other instrumentation. Although more elaborate methods can be used to constrain the top foil radial movement, such as set screws or other fasteners, the current method provides adequate performance, flexibility, and ease of manufacturing.

\section{Tooling and Fabrication}

Typically, foil thrust bearings consist of a discrete number of thrust pads, each having an arcuate shape where a top foil extends circumferentially with constant inner and outer diameters from the leading edge of the pad to the trailing edge. Since the top foil generally defines the boundaries of the gas film, the pad extent is taken in this configuration as the angular distance from leading to trailing edge of the top foil, independent of the details of the compliant understructure. Because this shape does not easily lend itself to common sheet metal forming equipment, the foil blanks used to construct the pads are cut around the perimeter using wire electrical discharge machining (EDM). Other methods commonly used as described in the open literature include stamping and chemical milling processes.

A bearing backing plate, as shown in Fig. 3, is first machined and surface ground to produce flat and parallel faces. The partial-arc slots needed to retain the foil components are then machined by wire EDM. Conveniently, slot thicknesses achievable by a single wire pass are appropriate to accommodate the practical range of foil thicknesses, leaving a small clearance in the hinge to permit motion. The backing plate is constructed from a nickel-based superalloy (Inconel 718) to allow heat treatment of the entire assembled bearing, as well as to permit high temperature operation. However, other dimensionally stable materials, such as precipitation hardened stainless steel, can conceivably be used for this component as operational conditions dictate.

The top and bump foil blanks are cut from stacks of annealed Inconel X-750 foil by the same EDM process. Dimensions of the foil blanks are given in Figs. 5 and 6, where the bump foil has several azimuthal slits separating it into five individual bump strips, as described by Gray and Heshmat [16]. This configuration allows for variable bump spacing which helps to accommodate the effects of varying surface velocity, thermal crowning, centrifugal dishing, and misalignment. The rectangular tabs are sized to fit into the backing plate slots.

There is a great deal of freedom in the design of the tooling required to form the bump foils. Although stamping or hydroforming methods may be appropriate for higher volume production designs, they are not as well-suited to one-off prototype designs. For this application, a rather traditional set of conventionally-machined dies is selected, and bump foils blanks are pressed into the dies for forming. This arrangement mimics the method reported by DellaCorte et al. [2], who describe a set of bump foil dies for foil journal bearings that provide for relatively inexpensive fabrication of various bump configurations.

In practice, the same tooling intended to create bump foils for journal bearings can be adapted to press bump foils for thrust bearings. This tooling usually has parallel corrugations, and a thrust bearing bump foil blank can be pressed into that tooling in the same way as a journal bearing blank. This method is attractive in that it requires little additional equipment beyond what is required to fabricate journal bearings. However, to demonstrate 


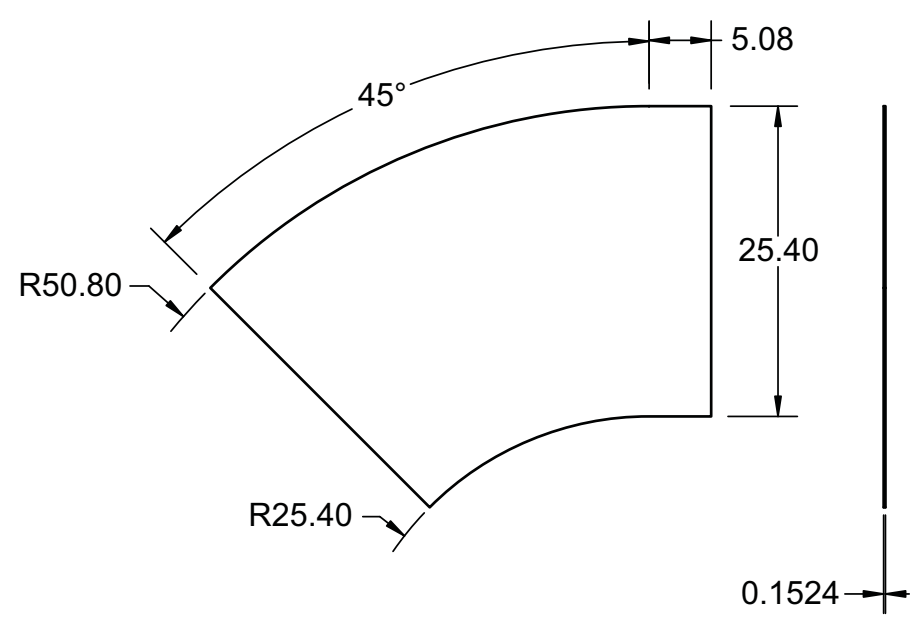

Figure 5. Drawing of Top Foil Blank (dimensions in $\mathrm{mm}$ )

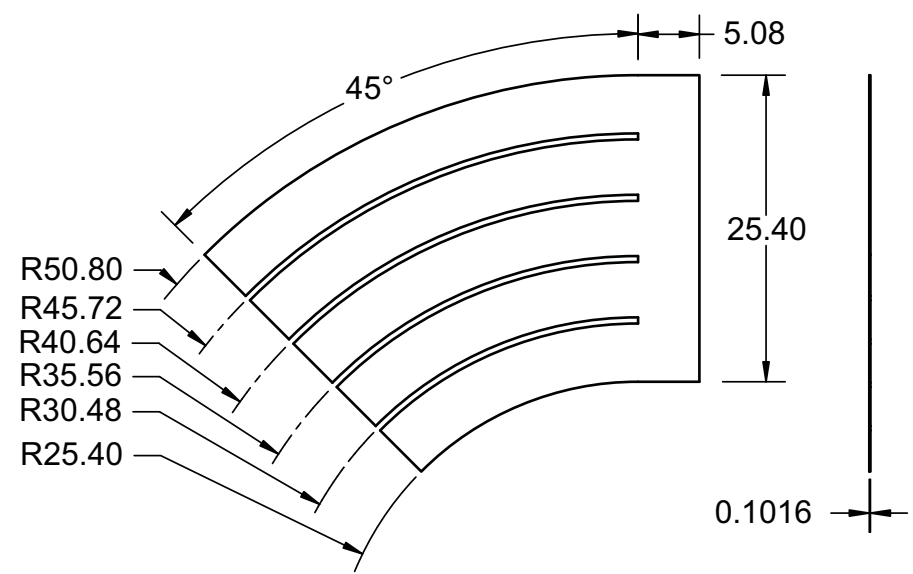

Figure 6. Drawing of Bump Foil Blank (dimensions in $\mathrm{mm}$ )

an alternate configuration the authors have chosen an arrangement where all bumps are oriented radially.

The bump foil die begins as a circular disk constructed from a suitable steel, such as 15-5 PH [2], which has been ground flat and parallel. Channels are then machined into the disk, corresponding to the desired corrugated bump profiles. These channels have a profile achieved by milling $508 \mu \mathrm{m}$ deep with a 3.175 $\mathrm{mm}$ ball end mill, which approximates the bump profiles as described by Ruscitto et al [23] and Heshmat et al [24]. A number of different arrangements can be employed, including a conventional milling machine with the workpiece held on a rotary table or dividing head, or with the piece held fixed in a computer numeric control (CNC) mill. This provides several options for a general machine shop to fabricate the tooling without specialized equipment.
Whereas the bump spacing in foil journal bearings is typically described by a linear bump pitch, the radially-oriented bumps in this design are separated by prescribed angular separations. For this work, the die disk has been divided into four sections where the radial channels are spaced by $5,7,9$, and $11^{\circ}$ respectively, as shown in Figure 7. Each of these sections contains bump rows extending approximately $60^{\circ}$ to allow construction of bearings with pad extents longer than the standard $45^{\circ}$ shown here. To allow bump foils to be constructed with azimuthal strips of varying bump spacing, the plate is separated into five concentric rings using wire EDM. The rings can then be rotationally indexed to produce a wide array of different bump foil configurations, as shown in Figure 8.

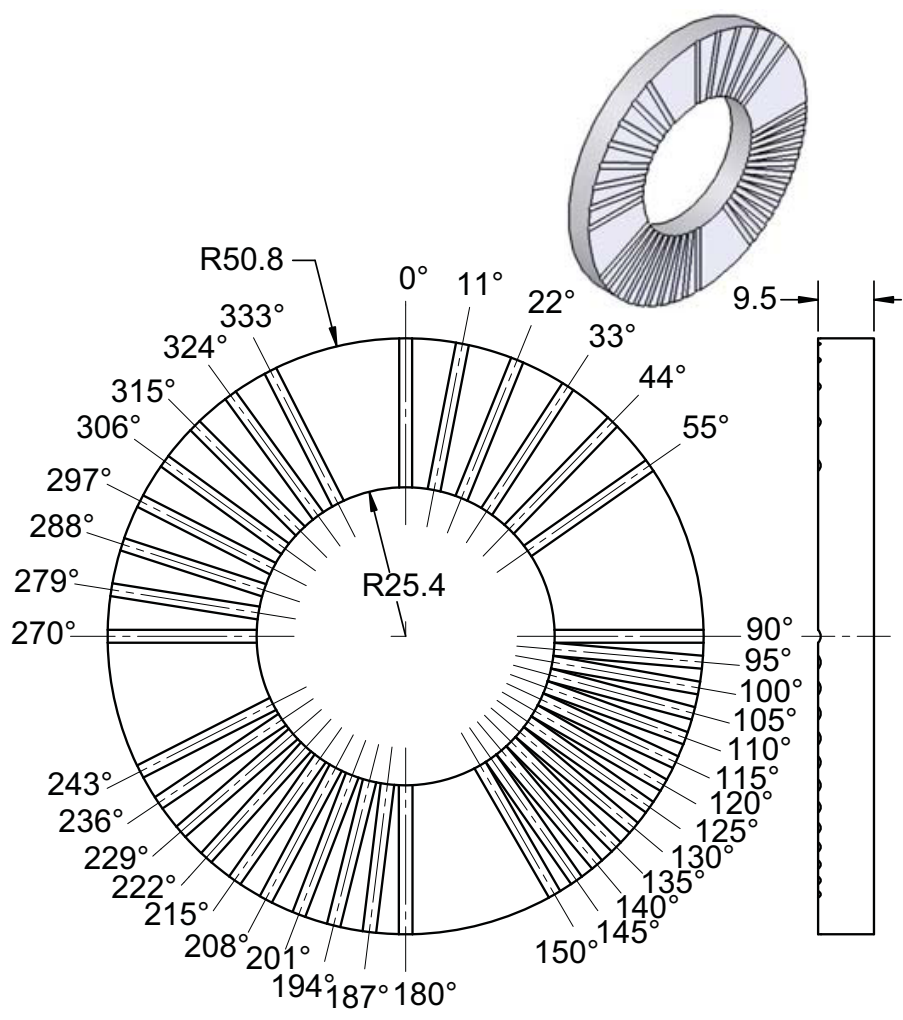

Figure 7. Drawing of Bump Foil Die with Radial Channels (dimensions in $\mathrm{mm}$ )

The bump foil blanks (Fig. 6) are arranged on the die to produce the desired bump layout and a $1.6 \mathrm{~mm}$ thick layer of polytetrafluoroethylene (PTFE) is placed over the foil, with a thick steel block resting on top (Fig. 9). This stack is then placed in a manual hydraulic press and approximately $20 \mathrm{MPa}$ of pressure is applied to form the bump foils. Figure 10 shows the bump foil and PTFE after forming, where the cold flow behavior of 


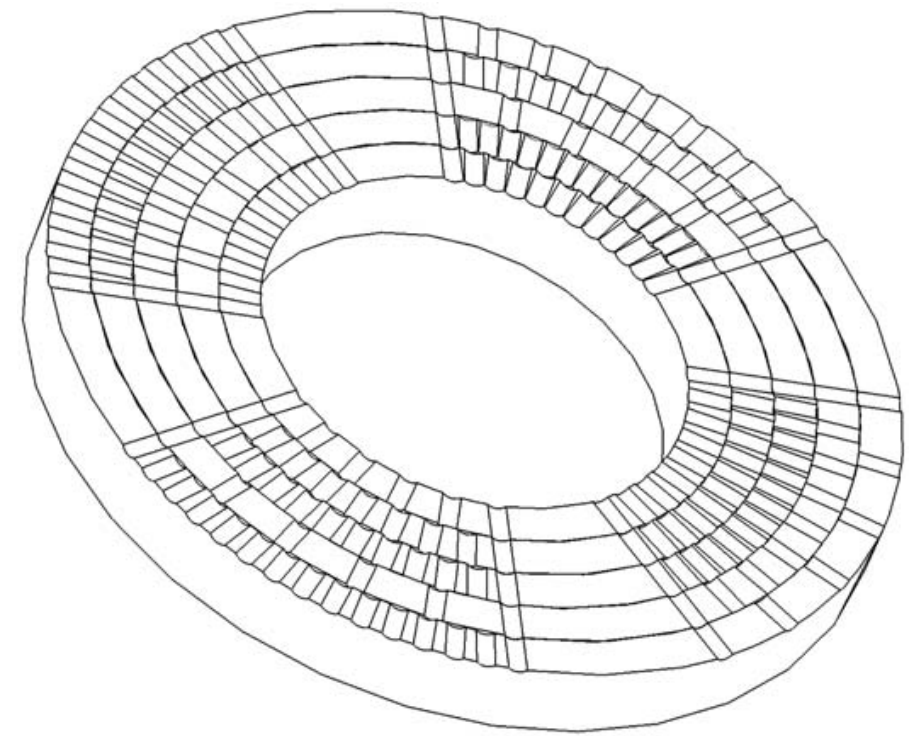

Figure 8. Drawing of Bump Foil Die with Indexed Concentric Rings

the PTFE was found to produce better-formed bumps than the polyurethane and rubber sheets also tested.

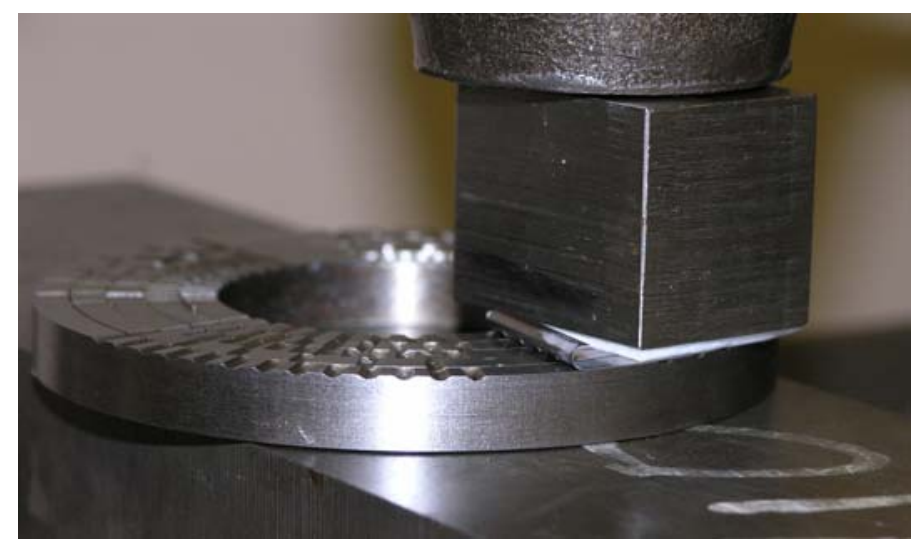

Figure 9. Bump Foil Being Formed in Hydraulic Press

After formation of the top and bump foils, the hinged edges of the foils (Fig. 4) are curled in situ by bending them into the backing plate slots. A $3.2 \mathrm{~mm}$ diameter pin is used in conjunction with the backing plate to aid in the forming. Because this forming operation is done by working the foil directly into the plate, no additional specialized fixtures and tools are required for this operation. Photographs of the prototype bearing during and after assembly are shown in Figures 11 and 12.

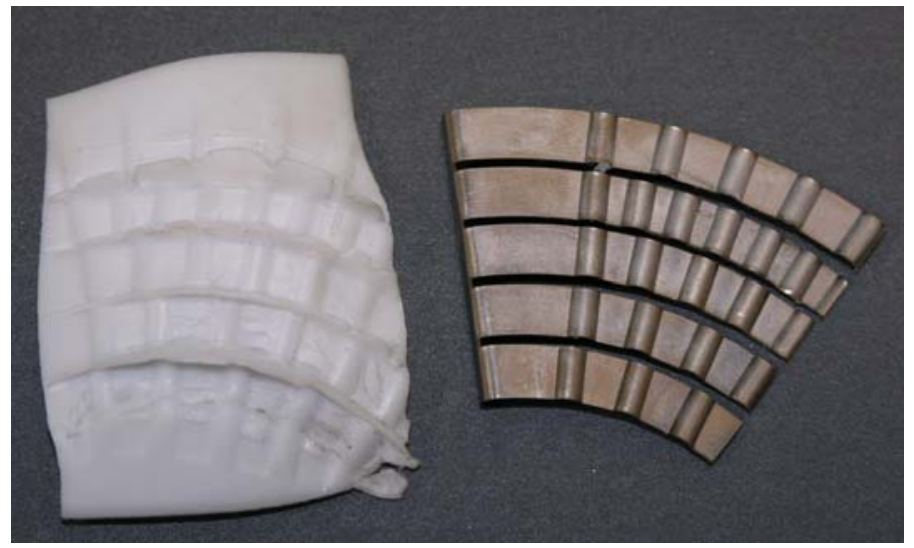

Figure 10. Bump Foil and PTFE After Forming

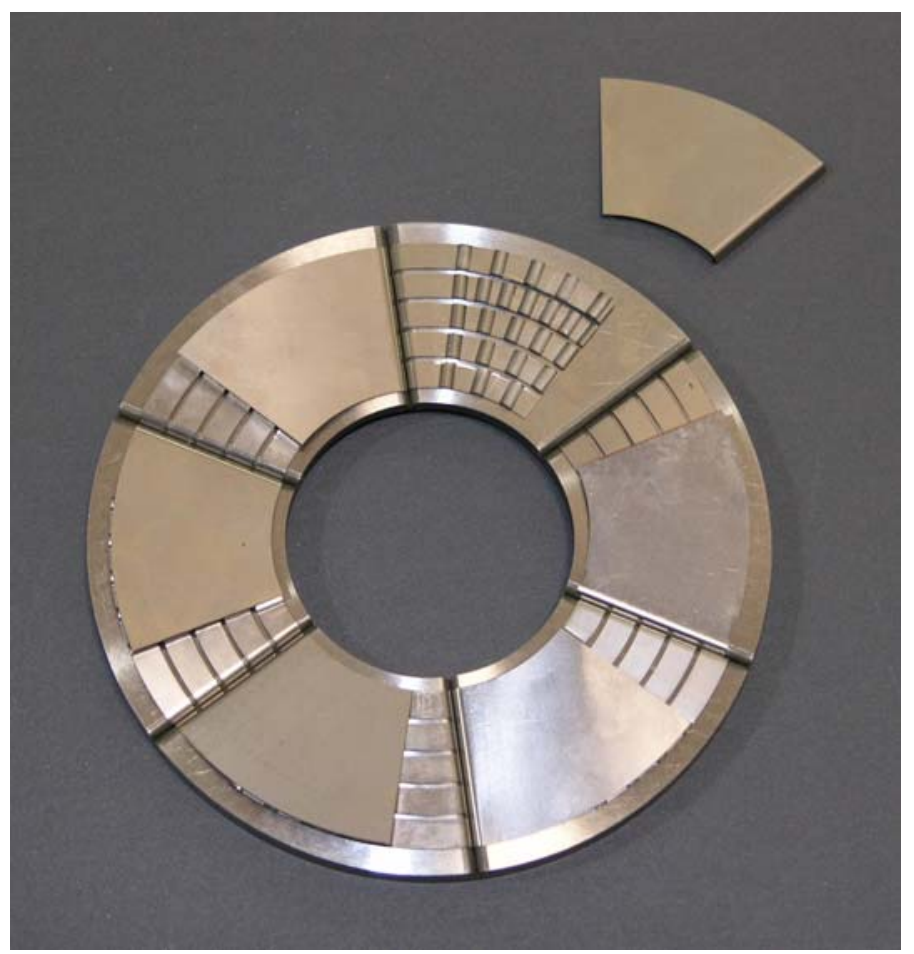

Figure 11. Prototype Bearing with One Top Foil Removed

Following the final forming steps of the foil members, metal straps are spot welded in the slots immediately adjacent to the inner and outer radii of the foils to prevent radial motion of the foils (shown in Fig. 12). Due to the arcuate nature of the pads, frictional torque exerts a radially inward force on the top foil when it is restrained on the leading edge, making the inner straps more critical to proper bearing operation. With the bearing fully assembled in this manner, there is a small amount of motion per- 


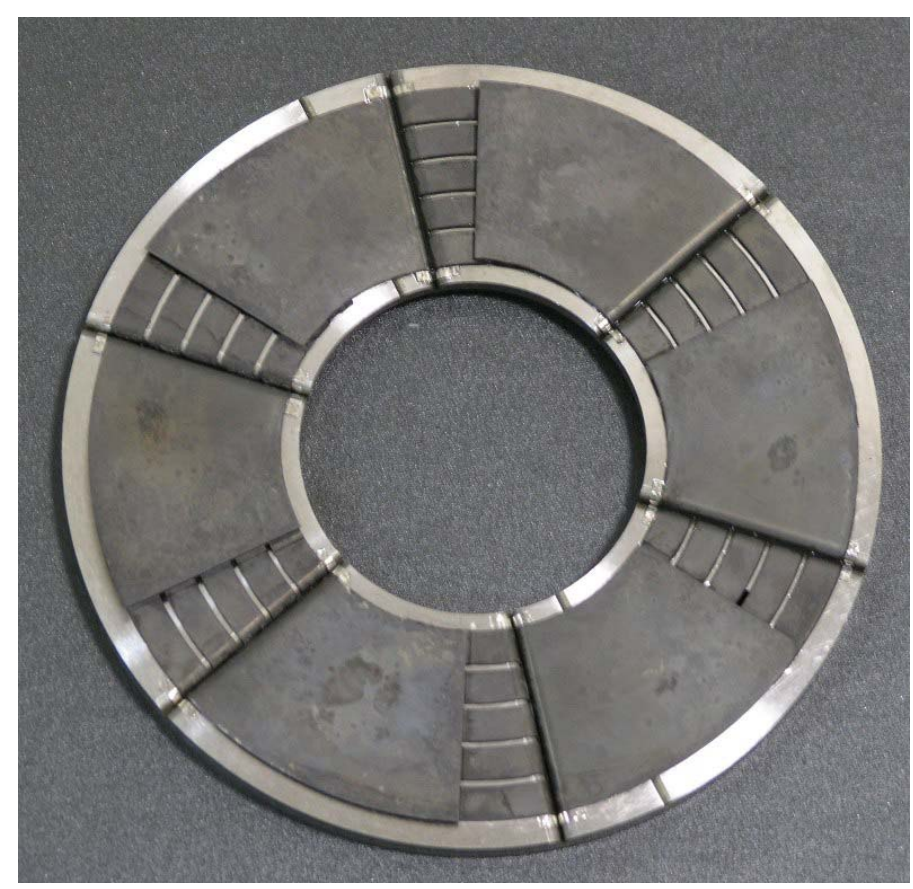

Figure 12. Photograph of Assembled Prototype Bearing after Heat Treatment of Foils

mitted in the hinge point of the top foil, though this is adjustable based on the thickness of the slot created by wire EDM. The bearing is then heat treated as an assembly.

To properly form the top foils during heat treatment, they are seated against the bump foils under a small compressive force of $2 \mathrm{kPa}$, based on the total top foil area. Circular plates appropriately massed for this purpose and compatible with the heat treatment temperatures have demonstrated acceptable performance in this study when rested on top of the bearing during the treatment. The Inconel X-750 alloy commonly used for bearing foils is generally supplied in the annealed or solution heat treated state, in which it is formed into the appropriate bearing members. From these states, various heat treatments are possible to achieve desirable mechanical properties, some of which are described by DellaCorte et al [2]. For information on the recommended heat treatments for Inconel X-750 as well as other nickel- and cobaltbased alloys, the reader is referred to AMS 2774A [25].

Prototype bearings are heat treated at $732^{\circ} \mathrm{C}$ for 16 hours, followed by an air cool, per AMS 5698. Although this AMS specification is intended for cold drawn wire, it has been found to be appropriate for the thin foil employed in these bearings. This heat treatment is chosen because it provides acceptable elastic properties at elevated temperatures in excess of $540^{\circ} \mathrm{C}$, but does not require an inert gas or vacuum environment. In general practice however, it may be desirable to conduct this heat treatment in a non-oxidizing atmosphere to better control the foil surface

\begin{tabular}{|l|l|}
\hline Inner Diameter & $5.08 \mathrm{~cm}$ \\
\hline Outer Diameter & $10.16 \mathrm{~cm}$ \\
\hline Pad Angular Extent & $45^{\circ}$ \\
\hline Single Pad Area & $7.6 \mathrm{~cm}^{2}$ \\
\hline Number of Pads & 6 \\
\hline Total Pad Area & $45.6 \mathrm{~cm}^{2}$ \\
\hline Top Foil Coating & N/A - bare Inconel X750 \\
\hline Top Foil Thickness & $152 \mu \mathrm{m}$ \\
\hline Bump Foil Thickness & $102 \mu \mathrm{m}$ \\
\hline Number of Bump Foil Strips & 5 \\
\hline Bump Pitches (I.D. to O.D.) & $\begin{array}{l}5.36,5.19,4.65,3.77, \\
\text { and 5.90mm }\end{array}$ \\
\hline
\end{tabular}

Table 1. Prototype Bearing Geometry

chemistry and prevent alloying constituents from being depleted due to surface oxidation.

\section{Prototype Geometry}

Based on the basic design principles outlined in the preceding section and dimensions available in the open literature, a prototype bearing geometry is selected, with relevant dimensions given in Table 1. These dimensions are chosen in most cases out of convenience and no attempt has been made to optimize performance by varying these parameters. For detailed analysis on foil thrust bearings, as well as available geometry and performance data, the reader is referred to refs [3], [17], [18], [20], [26], [27], [28], [29], [30].

Foil thrust bearings typically contain four to eight pads with individual angular extents of approximately $45^{\circ}$ and a ratio of outer radius to inner radius of about two. Heshmat et al provide a detailed optimization study concerning these bearing parameters [29]. The bearing described here contains six identical pads each with an angular extent of $45^{\circ}$ and a radius ratio of exactly two to represent typical thrust bearing designs.

Agrawal [22], who describes a somewhat more complex foil thrust bearing than is undertaken in this study, notes that a bearing intended for a 50,000-100,000 rpm turbocompressor for an air cycle air conditioning system would typically have a 127-152 $\mu \mathrm{m}$. thick top foil and an overall diameter of $10.16 \mathrm{~cm}$. Based on this guidance, the outer diameter of the prototype bearing is set at $10.16 \mathrm{~cm}$, and the top foil thickness is chosen to be $152 \mu \mathrm{m}$.

While the individual bump geometry can vary widely, a bump depth of $500 \mu \mathrm{m}$ is selected for the prototype bump foil 
die based on data taken from refs. [3] and [13]. Although the referenced designs incorporate bumps that vary slightly in height along the extent of the pad, the bump heights in the prototype design are nominally equal, and the converging wedge geometry is developed from the hinged leading edge to the first bump. Iordanoff [17] [18] provides comprehensive analysis of the gas film profile which is a useful tool to improve on the bump geometry employed in this study. The radius of curvature for the bump is chosen to be $1.6 \mathrm{~mm}$, as produced by a $3.2 \mathrm{~mm}$ diameter $(1 / 8$ inch) ball end mill. Bump foil thickness is chosen to be approximately $100 \mu \mathrm{m}$. to mimic forming characteristics reported by DellaCorte et al [2]. Each bump foil blank is divided into five bump strips of equal radial extent, ignoring the slit widths.

Heshmat [13] reports a radially-varying compliance distribution that puts the stiffest bump strips at the radial center of the pad, a soft bump strip on the inner radius where unit loading is lightest, and a medium bump stiffness on the outer diameter where loads are moderate, but increased compliance is required to accommodate misalignment. This qualitative design is chosen for the prototype bearing bump foil in order to demonstrate the capabilities of the indexable tooling previously described. Starting from the innermost bump strip and progressing radially outward, angular bump spacings of $11^{\circ}, 9^{\circ}, 7^{\circ}, 5^{\circ}$, and $7^{\circ}$ provide approximate midline bump pitches of 5.36, 5.19, 4.65, 3.77, and $5.90 \mathrm{~mm}$, respectively.

\section{Preliminary Test Results}

After assembly of a prototype bearing, several experimental tests are performed to verify proper bearing operation. A loaddeflection test of the bearing is first performed to ensure that the chosen complaint structure provides aggregate stiffness characteristics within an appropriate range for a bearing of this size. Figure 13 shows the average deflection of the bearing for various applied loads, where the load is reported per unit pad area. This shows an incremental bearing stiffness per pad area in the range of 1-10 $\frac{\mathrm{N}}{\mathrm{mm}^{3}}$ for unit loadings of 7-70 $\mathrm{kPa}$.

Following the load-deflection test, the bearing is subjected to elevated temperature $\left(425^{\circ} \mathrm{C}\right)$ start-stop cycling against a PS304 [31] [32] solid lubricant-coated thrust runner to simulate the early surface-conditioning process that is expected to occur in a turbomachine application. During these cycles, a constant axial load of approximately $7 \mathrm{kPa}$ is applied to the bearing as the runner is accelerated from rest to $20,000 \mathrm{rpm}$, held for a short time, and decelerated to a stop over a total-cycle period of about 15 seconds. This cycle profile exposes the bearing to dry sliding contact at low speeds as well as full-airborne operation at higher speeds, as would be experienced in practical applications. Figure 14 is a post-test photograph of a thrust bearing top foil showing characteristic top foil wear after cycling at high temperature.

After this initial conditioning test of more than 1000 cycles, the bearing is run at a constant speed of $23,000 \mathrm{rpm}$ while in-

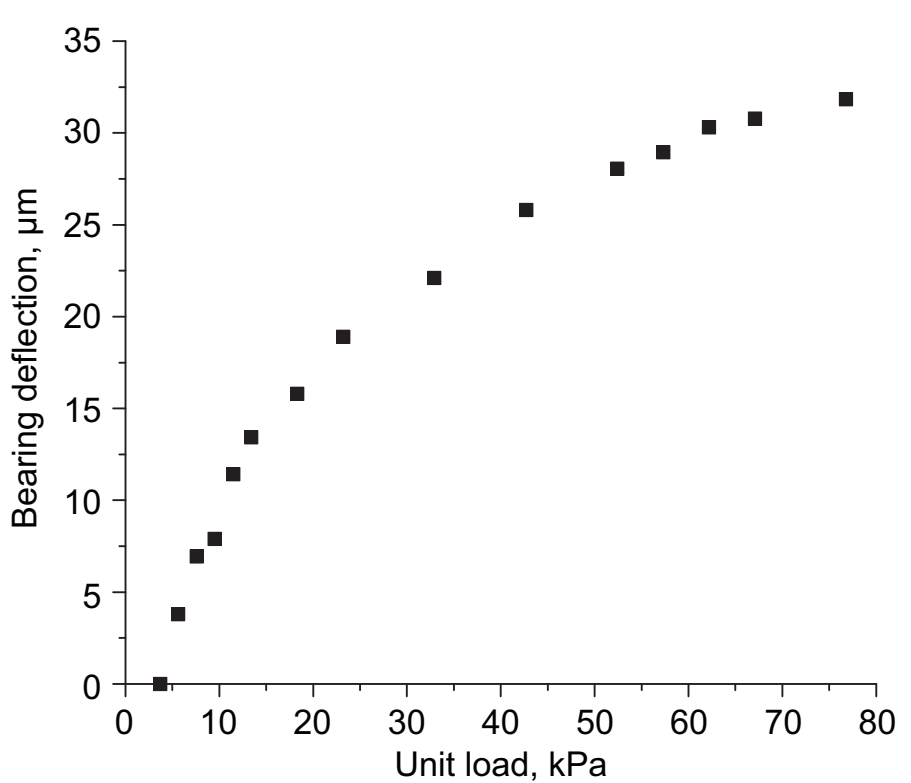

Figure 13. Load-Deflection Curve for Prototype Bearing

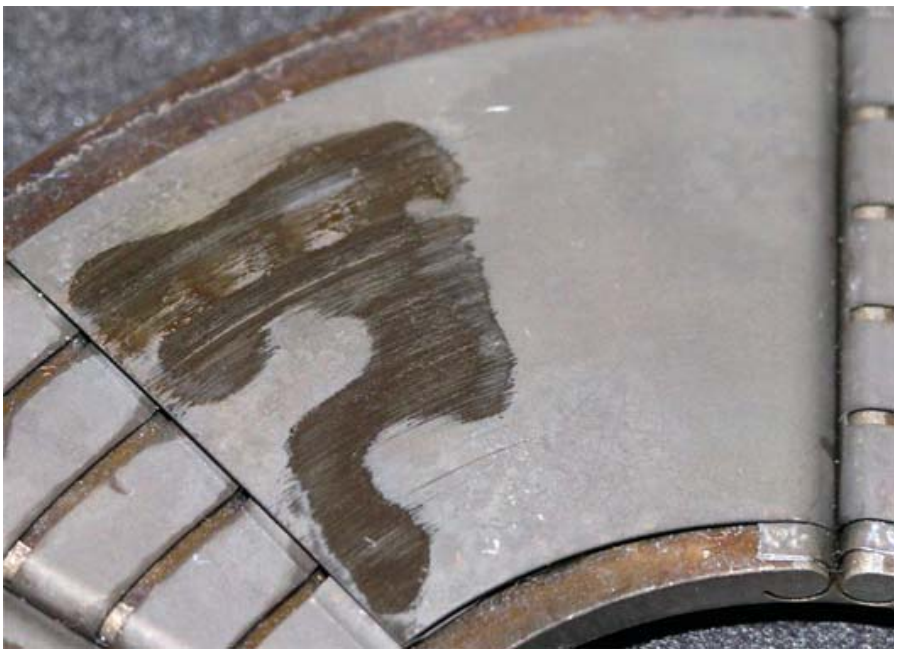

Figure 14. Wear Pattern on Top Foil after Start-Stop Cycling at High Temperature

creasing axial load in increments of 4-10 $\mathrm{N}$ followed by several minutes of dwell time at each load. Load capacity is reached when a large increase in torque accompanies a very small increase in load. Figure 15 shows the load-torque curve at 23,000 $\mathrm{rpm}$, where the load capacity is determined to be $125 \mathrm{~N}$. This is a modest value of load capacity, but it demonstrates the viability of this bearing design for parametric studies.

To compare the load capacity performance of the prototype bearing to published data, it is important to take into account, at 


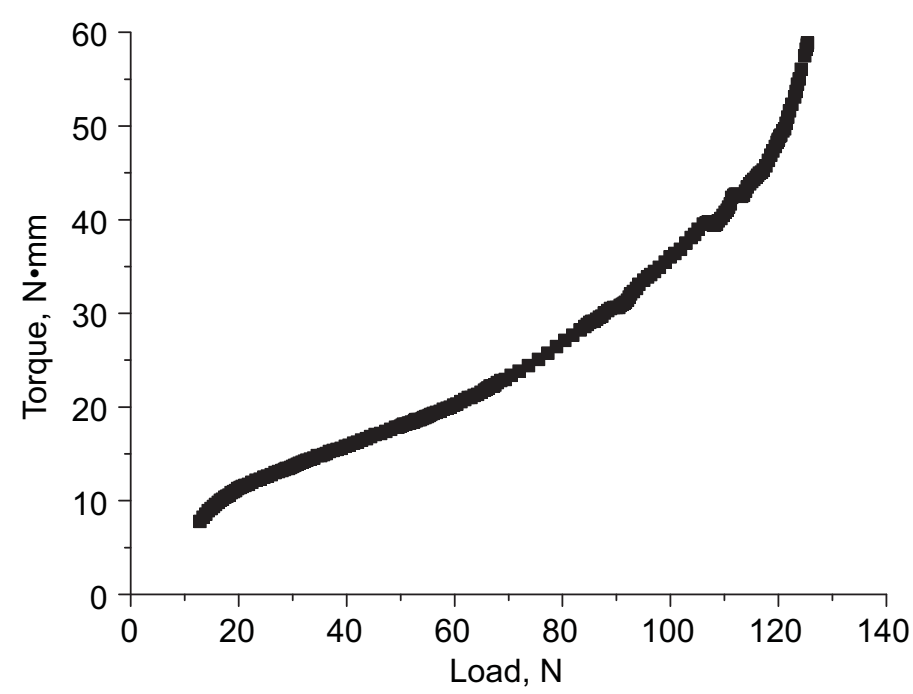

Figure 15. Torque versus Load at $23,000 \mathrm{rpm}$

a minimum, the bearing geometry and operating speeds. DellaCorte and Valco [33] report a simple rule-of-thumb model to aid in comparing the relative performance of various foil journal bearings, where the load capacity is determined to be a linear function of bearing surface velocity and bearing projected area, multiplied by a performance coefficient characteristic to the bearing design.

This expression provides an estimate of bearing performance based on the fundamental principles of hydrodynamic lubrication, and it is anticipated that a similar performance model can be developed for foil thrust bearings. The equivalent mathematical expression for thrust bearings, is given as:

$$
W=D_{t}\left(\pi w D_{m}\right)\left(D_{m} N\right)
$$

where:

$W$ is the maximum steady-state load, $\mathrm{N}$ (lbs)

$D_{t}$ is the load capacity coefficient, $\frac{N}{\mathrm{~mm}^{3} \mathrm{krpm}}\left(\frac{l b_{f}}{i \mathrm{in}^{3} \mathrm{krpm}}\right)$

$w$ is the difference between the inner and outer top foil diameters, $\mathrm{mm}$ (in.)

$D_{m}$ is the average of the inner and outer top foil diameters, $\mathrm{mm}$ (in.)

$N$ is the shaft speed in thousand rpm (krpm)

This expression describes thrust bearing load capacity as proportional to the runner surface velocity at the radial center of the top foil, and the total swept area of the bearing between the inner and outer radii of the foils. The bearing load capacity coefficient, when multiplied by these quantities, can provide a rough estimate of the maximum load the bearing can support, which is useful for feasibility and sizing studies.

Defined in this manner, the load capacity coefficient has units of force $\times$ time divided by length cubed, or viscosity per length. Physically, this reflects the ratio of the gas viscosity to the minimum tolerable (characteristic) film thickness, which is related to bearing and runner geometry, surface roughness, and details specific to the bearing design. For advanced bearing designs which more efficiently shape the film thickness distribution, this characteristic minimum film thickness is lowered, and higher load capacity performance is achieved.

Many foil thrust bearings do not have top foils that fully populate the swept area between the inner and outer pad diameters. The above expression conspicuously omits a factor which accounts for the portion of bearing area populated with load carrying top foils; this a consequence of system-level considerations. As noted earlier, turbomachine design practices favor a thrust runner with a minimized outer diameter. As such, the design of foil thrust bearings should favor the smallest required outer diameter to support a given load with adequate margin, and thus optimize the populated area to achieve that goal. If individual pads must have an angular separation to accommodate thermal management schemes or other design features, this expression for load capacity accounts for the associated spatial penalties and thus encourages the overall bearing design to be optimized.

It is notable that factors such as low-friction tribological coatings, effective thermal management, and highly smooth and flat surfaces have all been found to affect load capacity performance in foil thrust bearings [34], consistent with the physical interpretation of the load capacity coefficient as defined. As a result, a particular bearing design can exhibit a wide range of load capacity coefficients. However, this simple expression may be useful in comparing the relative performance of various bearings, holding other factors such as surface roughness and coatings constant.

The open literature contains few reports of experimentally measured foil thrust bearing load capacity. Furthermore, many of these load capacity data are reported without the combination of geometry and speed conditions necessary to calculate a load capacity coefficient according to the proposed expression. Nevertheless, a few data are available containing all the necessary information to estimate a load capacity coefficient.

While not the same structural configuration as the foil thrust bearings under study here, Licht [14] gives a load capacity equivalent to a $D_{t}$ of $0.027 \frac{l b_{f}}{i n^{3} \mathrm{krpm}}$ for a type of compliant thrust bearing. Koepsel [27] reports achieving a steady load capacity corresponding to a $D_{t}$ of 0.091 . Heshmat and Shapiro [3] discuss the development of two designs for foil thrust bearings, achieving load capacity coefficients of 0.034 and 0.048 at $80 \mathrm{krpm}$. It is notable that these two bearings were only about $50 \%$ and $67 \%$ populated with top foils, however. In a more recent study with 
a fully populated bearing running at speeds from $25-40 \mathrm{krpm}$, Dykas [34] reports load capacities corresponding to a coefficient of 0.125 with a commercially available bearing. However, even this more recent data is obtained from a bearing design several years old, and the authors are not aware of sufficient details on the load capacities of state-of-the-art foil thrust bearings in the open literature to report currently achievable coefficients. It is anticipated that this data will become more readily available in the near future. The single load capacity datum taken for the prototype bearing achieves an uncooled load capacity coefficient of 0.024 for a $75 \%$ populated bearing with bare Inconel X-750 foils and a runner surface roughness of $R_{a}=0.36 \mu m$, demonstrating a useful load capacity for parametric study. Furthermore, a visual inspection of post-test bearing wear suggests poor padto-pad consistency, implying that better quality control may improve performance.

\section{Concluding Remarks}

Using design methodologies laid out by DellaCorte, et al. [2], a basic foil thrust bearing design is outlined to demonstrate a modular bearing intended to provide rapid and low cost design iterations. The authors do not claim high load capacity or an optimized bearing, preferring instead to demonstrate the relative ease with which a simple foil thrust bearing can be constructed for experimental testing. With a modest investment in similar tooling, bearing backing plates, and foil material, marginal costs for subsequent bearing designs can be relatively low.

Initial performance data obtained from the test bearing described herein demonstrates a working prototype, and thus verify the basic methods by which it has been constructed. Further refinements of these methods are easily achievable by foil bearing practitioners wishing to adopt a bearing architecture conducive to parametric testing and low cost.

\section{REFERENCES}

[1] DellaCorte, C., and Pinkus, O., 2000. Tribological Limitations in Gas Turbine Engines: A Workshop to Identify the Challenges and Set Future Directions. NASA TM 2000210059, National Aeronautics and Space Administration, Cleveland, $\mathrm{OH}$.

[2] DellaCorte, C., Radil, K., Bruckner, R. J., and Howard, S. A., 2007. Design, Fabrication and Performance of Open Source Generation I and II Compliant Hydrodynamic Gas Foil Bearings. NASA TM 2007-214691, National Aeronautics and Space Administration, Cleveland, $\mathrm{OH}$.

[3] Heshmat, H., and Shapiro, W., 1984. "Advanced Development of Air-Lubricated Foil Thrust Bearings". Lubrication Engineering, 40(1), pp. 21-26.

[4] Valco, M. J., and DellaCorte, C., 2002. "Emerging OilFree Turbomachinery Technology for Military Propulsion and Power Applications". In Proceedings of the 23rd U.S. Army Science Conference.

[5] DellaCorte, C., Radil, K., Bruckner, R. J., and Howard, S. A., 2007. A Preliminary Foil Gas Bearing Performance Map. NASA TM 2007-214691, National Aeronautics and Space Administration, Cleveland, $\mathrm{OH}$.

[6] Howard, S. A., 2007. A New High-Speed Oil-Free Turbine Engine Rotordynamic Simulator Test Rig. NASA TM 2007-214489, National Aeronautics and Space Administration, Cleveland, $\mathrm{OH}$.

[7] DellaCorte, C., Radil, K., Bruckner, R., Bauman, S., Puleo, B. S., and Howard, S. A., 2006. "Rotor Support Technology Developments for Long Life Closed Brayton Cycle Turbines". In Proceedings of the Space Technology and Applications International Forum - STAIF 2006, American Institute of Physics.

[8] Blok, H., and vanRossum, J., 1953. "The Foil Bearing - A New Departure in Hydrodynamic Lubrication”. Lubrication Engineering, 9(6), pp. 316-320.

[9] Heshmat, H., 1981. Multi-Stage Support Elements for Compliant Hydrodynamic Bearings. U.S. Patent 4,300,806.

[10] Barnett, M., 1972. Self-Pressurizing Bearings with Resilient Elements. U.S. Patent 3,635,534.

[11] Silver, A., 1979. Foil Bearing Stiffener. U.S. Patent 4,153,315.

[12] Fortmann, W. E., 1978. Dual Wedge Fluid Thrust Bearing Including Wave Spring. U.S. Patent 4,082,375.

[13] Heshmat, H., 1981. Stepped, Split, Cantilevered Compliant Bearing Support. U.S. Patent 4,277,112.

[14] Licht, L., 1978. Resilient Foil Thrust Bearings. U.S. Patent $4,116,503$.

[15] Gu, A., and Nadjafi, R., 1993. Foil Thrust Bearing with Varying Radial and Circumferential Stiffness. U.S. Patent 5,248,205.

[16] Gray, S., and Heshmat, H., 1981. Support Element for Compliant Hydrodynamic Thrust Bearing. U.S. Patent $4,277,111$.

[17] Iordanoff, I., 1998. "Maximum Load Capacity Profiles for Gas Thrust Bearings Working Under High Compressibility Number Conditions". ASME Journal of Tribology, 120, pp. 571-576.

[18] Iordanoff, I., 1999. "Analysis of an Aerodynamic Compliant Foil Thrust Bearing: Method for a Rapid Design". ASME Journal of Tribology, 121, pp. 816-822.

[19] Agrawal, G., and Hockey, E., 1982. Foil Bearing Mounting. U.S. Patent 4,348,066.

[20] Ku, C. R., and Heshmat, H., 1992. "Compliant Foil Bearing Structural Stiffness Analysis: Part I - Theoretical Model Including Strip and Variable Bump Foil Geometry". ASME Journal of Tribology, 114, pp. 394-400.

[21] Heshmat, H., 1999. High Load Capacity Compliant Foil Hydrodynamic Thrust Bearing. U.S. Patent 5,961,217. 
[22] Agrawal, G., 1984. Hydrodynamic Fluid Film Thrust Bearing. U.S. Patent 4,462,700.

[23] Ruscitto, D., McCormick, J., and Gray, S., 1978. Hydrodynamic Air Lubricated Compliant Surface Bearing for an Automobile Gas Turbine Engine I - Journal Bearing Performance. NASA CR 135368, National Aeronautics and Space Administration, Cleveland, $\mathrm{OH}$.

[24] Heshmat, H., Shapiro, W., and Gray, S., 1982. "Development of Foil Journal Bearings for High Load Capacity and High Speed Whirl Stability". ASME Journal of Lurbication Technology, 104(2), pp. 149-156.

[25] Society of Automotive Engineers, 2005. Heat Treatment Wrought Nickel Alloy and Cobalt Alloy Parts Aerospace Material Specification AMS 2774A. Warrendale, PA.

[26] Heshmat, H., 1991. Analysis of Compliant Foil Bearings with Spatially Variable Stiffness. AIAA Paper AIAA-912102, American Institute of Aeronautics and Astronautics, Washington, D.C.

[27] Koepsel, W., 1977. Gas Lubricated Foil Bearing Development for Advanced Turbomachines. AFAPL-TR- 76-114, Air Force Aero Propulsion Laboratory, Dayton, $\mathrm{OH}$.

[28] Heshmat, C. A., Xu, D. S., and Heshmat, H., 2000. “Analysis of Gas Lubricated Foil Thrust Bearings Using Coupled Finite Element and Finite Difference Methods". ASME Journal of Tribology, 122, pp. 199-204.
[29] Heshmat, H., Walowit, J. A., and Pinkus, O., 1983. "Analysis of Gas Lubricated Compliant Thrust Bearings". ASME Journal of Lubrication Technology, 105, pp. 638-646.

[30] Bruckner, R. J., 2004. "Simulation and Modeling of the Hydrodynamic, Thermal, and Structural Behavior of Foil Thrust Bearings". PhD thesis, Case Western Reserve University, Cleveland, $\mathrm{OH}$.

[31] DellaCorte, C., and Edmonds, B. J., 1999. Self-Lubricating Composite Containing Chromium Oxide. U.S. Patent $5,866,518$.

[32] DellaCorte, C., and Edmonds, B. J., 1995. Preliminary Evaluation of PS300: A New Self-Lubricating High Temperature Composite Coating for Use to 800C. NASA TM 107056, National Aeronautics and Space Administration, Cleveland, $\mathrm{OH}$.

[33] DellaCorte, C., and Valco, M. J., 2000. "Load Capacity Estimation of Foil Air Journal Bearings for Oil-Free Turbomachinery Applications". Tribology Transactions, 43, pp. 795-801.

[34] Dykas, B. D., 2006. "Factors Influencing the Performance of Foil Gas Thrust Bearings for Oil-Free Turbomachinery Applications". PhD thesis, Case Western Reserve University, Cleveland, $\mathrm{OH}$. 


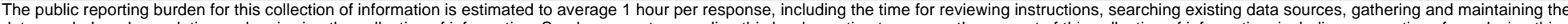

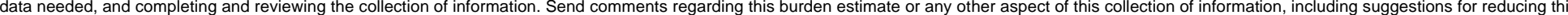

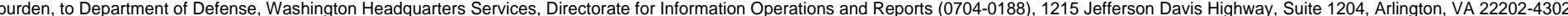

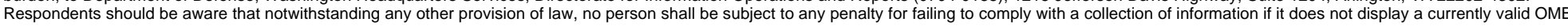
control number.

PLEASE DO NOT RETURN YOUR FORM TO THE ABOVE ADDRESS.

\section{REPORT DATE $(D D-M M-Y Y Y Y)$ \\ 2. REPORT TYPE \\ 3. DATES COVERED (From - To)}

01-01-2008

Technical Memorandum

\section{TITLE AND SUBTITLE}

Design, Fabrication, and Performance of Foil Gas Thrust Bearings for Microturbomachinery

Applications

5a. CONTRACT NUMBER

5b. GRANT NUMBER

5c. PROGRAM ELEMENT NUMBER

6. AUTHOR(S)

Dykas, Brian; Bruckner, Robert; DellaCorte, Christopher; Edmonds, Brian; Prahl, Joseph

\section{5d. PROJECT NUMBER}

5e. TASK NUMBER

5f. WORK UNIT NUMBER

WBS 877868.02.07.03.01.01

\section{PERFORMING ORGANIZATION NAME(S) AND ADDRESS(ES)}

National Aeronautics and Space Administration

8. PERFORMING ORGANIZATION

REPORT NUMBER

John H. Glenn Research Center at Lewis Field

E-16284

Cleveland, Ohio 44135-3191

\section{SPONSORING/MONITORING AGENCY NAME(S) AND ADDRESS(ES)}

National Aeronautics and Space Administration

Washington, DC 20546-0001

\begin{tabular}{l}
$\begin{array}{l}\text { 10. SPONSORING/MONITORS } \\
\text { ACRONYM(S) } \\
\text { NASA }\end{array}$ \\
\hline $\begin{array}{l}\text { 11. SPONSORING/MONITORING } \\
\text { REPORT NUMBER } \\
\text { NASA/TM-2008-215062; GT2008-50377 }\end{array}$
\end{tabular}

\section{DISTRIBUTIONIAVAILABILITY STATEMENT}

Unclassified-Unlimited

Subject Categories: 07 and 20

Available electronically at http://gltrs.grc.nasa.gov

This publication is available from the NASA Center for AeroSpace Information, 301-621-0390

\section{SUPPLEMENTARY NOTES}

\section{ABSTRACT}

A methodology for the design and construction of simple foil thrust bearings intended for parametric performance testing and low marginal costs is presented. Features drawn from a review of the open literature are discussed as they relate to bearing performance. The design of fixtures and tooling required to fabricate foil thrust bearings is presented, using conventional machining processes where possible. A prototype bearing with dimensions drawn from the literature is constructed, with all fabrication steps described. A load-deflection curve for the bearing is presented to illustrate structural stiffness characteristics. Start-top cycles are performed on the bearing at a temperature of 425 ${ }^{\circ} \mathrm{C}$ to demonstrate early-life wear patterns. A test of bearing load capacity demonstrates useful performance when compared with data obtained from the open literature.

\section{SUBJECT TERMS}

Gas bearings; Foil bearings; Thrust bearings

\begin{tabular}{|l|l|l|l|}
\hline \multicolumn{2}{|l|}{ 16. SECURITY CLASSIFICATION OF: } & $\begin{array}{l}\text { 17. LIMITATION OF } \\
\text { ABSTRACT }\end{array}$ \\
\begin{tabular}{|l|l|} 
a. REPORT \\
U
\end{tabular} & $\begin{array}{l}\text { b. ABSTRACT } \\
\text { U }\end{array}$ & $\begin{array}{l}\text { c. THIS } \\
\text { PAGE } \\
\text { U }\end{array}$ & UU \\
\hline
\end{tabular}

18. NUMBER
OF
PAGES
17
19a. NAME OF RESPONSIBLE PERSON STI Help Desk (email:help@sti.nasa.gov) 19b. TELEPHONE NUMBER (include area code) 301-621-0390



